\title{
AVANZA HACIA EL CONOCIMIENTO CIENTÍFI- CO - EXPERIENCIAS EDUCATIVAS CIENTÍFICAS DINÁMICAS SOCIALES DEL CONOCIMIENTO CIENTÍFICO TECNOLÓGICO
}

Magister Corvalán, Rubén Edgar; Ingeniero Sanabria, Norberto Argentino; Ingeniero Ibañez, Miguel Ángel, Licenciada Amarilla Alicia (*)

Lugar de trabajo: Universidad Nacional del Nordeste, UNNE, Facultad de Ciencias Exactas y Naturales y Agrimensura, FaCENA, Grupo Regional de Administración Tecnológica, Organizativa y Social, GRATOS, Departamento de Ingeniería.

Dirección: Avenida Libertad No 5460, Edificio del departamento de Ingeniería. CP 3400 Corrientes

Email: rubenpstt@yahoo.com.ar ; norbertosanabria@hotmail.com

Celulares: 3794585000 / 3794593090

Palabras Clave: vinculación tecnológica, experiencias educativas, ciencia didáctica

\section{Resumen:}

Es una actividad que se desarrolla desde la Facultad de Ciencias Exactas y Naturales y Agrimensura de la universidad nacional del Nordeste, consistente en una tarea eminentemente de Extensión y vinculación hacia el medio, con la participación principalmente de alumnos de las carreras de Ingeniería de la facultad. Quienes acompañados por sus profesores desarrollan kits educativos consistentes en experiencias didácticas sobre el desarrollo tecnológico referidos a las ramas de la ingeniería en colaboración con otras disciplinas, que permiten a modo de museo interactivo de las ciencias, que los alumnos de los niveles educativos desde el último año de la primaria, pasando por toda la secundaria y alumnos del primer año universitario , participen de manera lúdica e interactiva con estas experiencias , que se desarrollaron en distintos ámbitos en una presentación anual o semestral, en sus primeros años se desarrollaron en los salones del Edificio de física del campus universitario.

Posteriormente con el apoyo del $\mathrm{Mi}$ nisterio de Educación de las Provincia de Corrientes en los salones de actos de varias escuelas entre las que se incluyen, provincia de Salta, Bernardino Rivadavia y Juan $\mathrm{Pu}$ jol, y también con el apoyo del Instituto de Cultura de la provincia de Corrientes en el Anfiteatro Mario del Transito Cocomarola, y actualmente en el nuevo edificio del Departamento de Ingeniería del campus Deodoro Roca de la UNNE.

Cada una de estas experiencias que se vienen programando desde el año de las

(*) Grupo Regional de Administración Tecnológica, Organizativa y Social, GRATOS, Departamento de Ingeniería. Avenida Libertad No 5460, Email: rubenpstt@yahoo.com.ar ; norbertosanabria@hotmail.com 
ciencias en el 2008, tienen como misión el acercar a las ciencias y la tecnología a los niños y jóvenes; En cada presentación no solo participa la escuela anfitriona sino también los institutos educativos no solo de $\mathrm{Co}^{-}$ rrientes, sino de localidades vecinas como ser Riachuelo, San Luis del Palmar, Santa Ana y San Cosme entre otras. Que permitieron a los niños y jóvenes que no pudieron viajar a Tecnópolis, o si lo hicieron, parti- cipar en pequeño de una muestra de estas características. En estos años por más de treinta experiencias anuales han participado satisfactoriamente como lo acreditan las encuestas de satisfacción más de diez mil alumnos, pasando e interactuando por esta muestra de Vinculación Científica y Tecnológica, desarrollada a través de la Secretaria de Extensión de la FACENA.

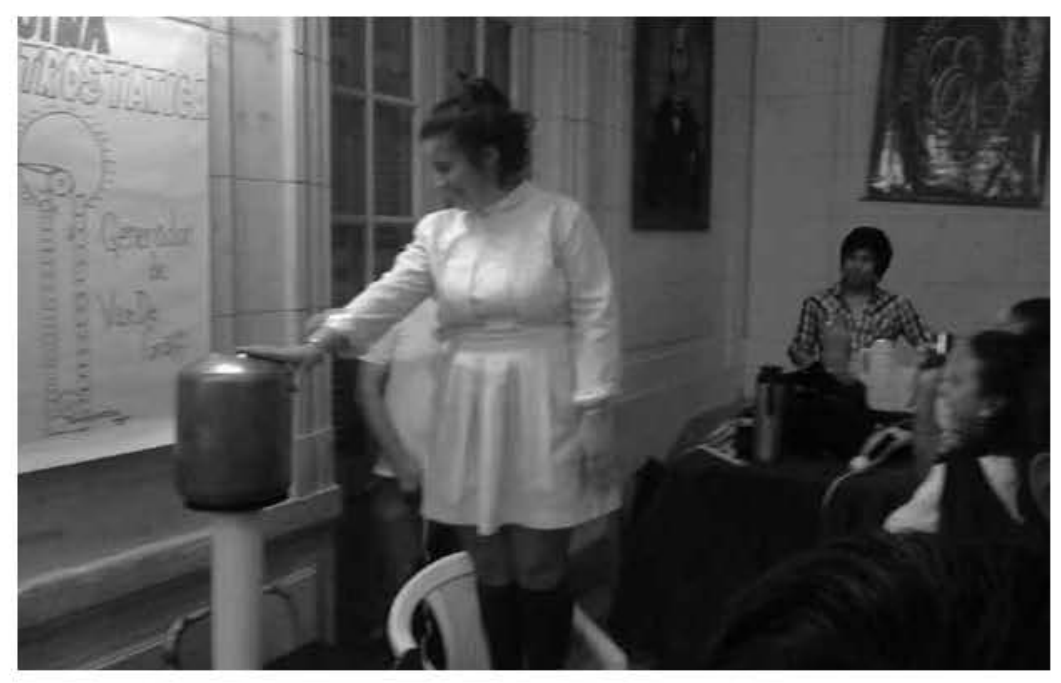

Avanza al Conocimiento Científico es el nombre que lleva el proyecto que organiza año a año la Cátedra "Seminario de Ingeniería” de las Carreras de Ingeniería Eléctrica y en Electrónica de la Facultad de Ciencias Exactas, Naturales y Agrimensura de la UNNE.

La dirección del proyecto está cargo de docentes y alumnos avanzados tiene por objetivo el motivar a niños y jóvenes y generar vocaciones científicas.

Este año las actividades centrales se llevan a cabo en el Edificio del Departamento de Ingeniería ubicado en el Campus Deodoro Roca de la UNNE. Durante las dos jornadas se previo la visita de alumnos de 1a Escuela Primaria del $\mathrm{B}^{\circ}$ San Jerónimo, la Escuela "Santa Ana, Escuela Agop Seferian, Instituto Nuevo Horizonte, Escuela $\mathrm{N}^{\circ} 296$ y la Escuela N³23 "Islas Malvinas" Sara Sáenz C s/n B0. Molina Punta.

La idea es mostrar experimentos científicos y generar vocaciones o conocimientos más cercanos a la ciencia en alumnos del nivel primario en la ciudad de Corrientes". En este sentido, estudiantes avanzados de la materia "Seminario de Ingeniería" Módulo V- de las Carreras de Ingeniería en Electrónica y Eléctrica trabajaron durante todo el primer cuatrimestre en alrededor de cuarenta proyectos científicos de carácter interactivo. 
Entre los prototipos educativos presentados se abordan temáticas como; El Brazo Eléctrico, El Generador Hidroeléctrico, Juegos de Señales Nerviosas, Tanque Elevado Electrónico, Iluminación Inteligente de Calles, Cartel Giratorio de Leds, Aparejos y Palancas y Burbujero Robótico. Todos los proyectos diseñados por los estudiantes de ingeniería de la UNNE buscan mostrar a los niños que la ciencia se puede aplicar a la vida cotidiana a través de juegos didácticos.
Las VI Jornadas de Experiencias Educativas y Científicas de nivel primario y secundario se realizo en conjunto con el Ministerio de Educación de la Provincia de Corrientes. Llegar, a través de experiencias educativas, a los alumnos de las instituciones educativas de Corrientes.

El mismo se denomina "Avanza hacia el conocimiento científico" en homenaje al ex secretario General de Ciencia y Técnica de la UNNE y docente e investigador de esa Facultad, Doctor Jorge Ramón Avanza.

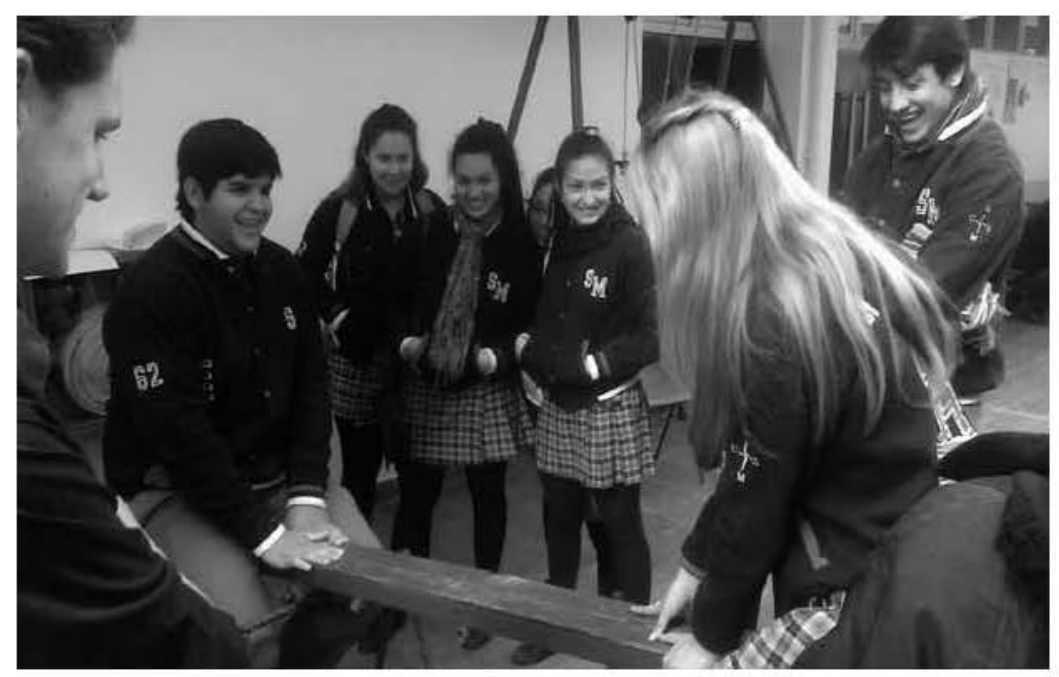

